\section{RESULTADOS}

El establecimiento de yemas in vitro de Rhododendron catawbiense "album" fluctuó entre un 65-100\%, lográndose la brotación bajo todos los tratamientos, sin diferencias estadísticamente significativas para los medios y concentraciones de fitohormonas. Solamente el parámetro longitud de brotes y tipo de explante estuvieron influenciadas por las concentraciones de fitohormonas, obteniéndose los brotes de mayor tamaño con una concentración de $2-4 \mathrm{mg} \mathrm{L}^{-1}$ de AIA y $5 \mathrm{mg}$ de 2iP, mientras que el tipo de explante que presentó una mayor regeneración fueron yemas aisladas sin tallo.
De esta forma se pudo establecer que el establecimiento de yemas aisladas de árboles adultos es una alternativa eficiente para realizar la incorporación in vitro y que los brotes inducidos pueden ser multiplicados eficazmente bajo estas condiciones.

\section{BIBLIOGRAFÍA}

ANDERSON, W.C. 1975. Propagation of rhododendrons by tissue culture: Part 1 . Development of a culture medium for multiplication of shoots. Proc. Intl. Plant. Prop. Soc. 25: 129-135.

ECONOMOU A.S.; READ. P.E. 1984. In vitro shoot proliferation of Minnesota deciduos azaleas. Hortscience 19: 60-61.

Agro Sur 34 (1-2):72-73 2006

\title{
PROYECTO RECUPERACIÓN Y MEJORAMIENTO DEL CACTARIO, PATRIMONIO NATURAL DE LA UNIVERSIDAD AUSTRAL DE CHILE.
}

\section{CACTUS COLLECTION RECOVERING AND IMPROVING PROYECT , NATURAL PATRIMONY OF THE UNIVERSIDAD AUSTRAL DE CHILE.}

\author{
Hermosilla, E. \\ Universidad Austral de Chile, Casilla 1235 Valdivia, \\ mariahermosilla@uach.cl
}

El Instituto de Botánica, el Proyecto de Administración Ambiental Corporativo y la Dirección de Extensión de la Universidad Austral de Chile, están desarrollando desde el año 2002 el Proyecto Recuperación y Mejoramiento de Cactario, Patrimonio Natural de la Universidad Austral de Chile.

El Proyecto tiene como objetivo principal mantener y ampliar la colección de plantas suculentas (Cactáceas y Crasas) que fue donada a la Universidad en 1992 por un coleccionista particular, el Sr. Roberto Binder, habilitándola para desarrollar en ella actividades de investigación, docencia y extensión. La colección está compuesta actualmente por más de 150 especies y posee dentro de sus ejemplares, algunas especies chilenas y especies exóticas raras o cuyo valor radica en la edad de los ejemplares, que superan en algunos casos los 40 años.

Considerando que en Chile la familia de las Cactaceae está representada por cerca de 200 especies, ubicadas en 22 géneros, y que de éstas, más de 180 son endémicas y se encuentran exclusivamente en territorio chileno, el conocimiento y difusión de su importancia y valor es relevante. Además, en el Libro Rojo de la Flora Terrestre de Chile, se mencionan 12 géneros en los cuales una o más especies tienen problemas de conservación. De ellas, 151 son endémicas. El escaso conocimiento que se tiene acerca de muchas de estas especies, el deterioro y alteración de hábitats en las regiones centrales y el aumento de la comercialización a coleccionistas privados o con otros fines, puede causar daños irreversibles en su sobrevivencia, por lo que dentro de los objetivos prioritarios del pro- 
yecto, se ha planteado aumentar el número de especies chilenas en el cactario y potenciar su conocimiento y difusión.

Por otro lado, se pretende desarrollar en docen- tes y estudiantes el interés por realizar investigación en el uso y potencialidades de estas plantas, entre ellas sus propiedades antirradiación, para lo cual se están preparando ejemplares que 